\title{
O PAPEL DA SUPERVISÃO ESCOLAR NO CONTEXTO ATUAL
}

\author{
Marilza de Lourdes Thomazini Stinguel ${ }^{1}$
}

\begin{abstract}
RESUMO
Este estudo traz a baila uma breve reflexão de cunho científico sobre a supervisão escolar no contexto atual, que se constitui num trabalho profissional que tem o compromisso juntamente com os professores de garantir os princípios de liberdade e solidariedade humana, no pleno desenvolvimento do educando, no seu preparo para o exercício da cidadania e sua qualificação para o trabalho e, para isso assegurar a qualidade de ensino, da educação, da formação humana nos diversos contextos que emergem em nossa sociedade.

Palavras- chaves: Supervisão Escolar, Trabalho profissional e Educação
\end{abstract}

\section{INTRODUÇÃO}

No atual contexto da educação brasileira, cresce a importância do supervisor educacional, que representa uma das pessoas que procura direcionar o trabalho pedagógico na escola em que atua para que se efetive a qualidade em todo o processo educacional.

Sabe-se que o Supervisor Escolar no contexto atual é um servidor especializado em manter a motivação do corpo docente, deve ser um idealista, definindo claramente que caminhos tomar, que papéis se propõe a desempenhar, buscando constantemente ser transformador, trabalhando em parceria, integrando a escola e a comunidade na qual se insere.

\section{DESENVOLVIMENTO.}

O supervisor, na atual realidade, deve ser capaz de pensar e agir com inteligência, equilíbrio, liderança e autoridade, valores esses que requerem habilidade para exercer suas atividades de forma responsável e comprometida no contexto que emerge em nossa sociedade. Na década de 90, a supervisão era apontada como instrumento necessário para mudança nas escolas. Justamente nesta década, segundo Ferreira ${ }^{2}$ (2003, p. 74):

\footnotetext{
${ }^{1}$ Licenciatura Plena em Letras: Português/Francês pela Faculdade de Filosofia, Ciências e Letras de Colatina - FAFIC. Pós-graduada em Planejamento Educacional pela Universidade Salgado de Oliveira - UNIVERSO, Pós-graduada em Gestão Escolar Integradora: Supervisão, Orientação e Inspeção Educacional pelo Instituo de Apoio e Desenvolvimento Empresarial e Educacional - IADE E-mail: marilzathomazini@hotmail.com.

2. FERREIRA, Naura S. C. Supervisão Educacional para uma escola de qualidade: formação a ação. 4 ed., São Paulo: Cortez, 2003, p.74.
} 
[...] desempenha-se o supervisor competente, entendendo-se que a competência é, em si, um compromisso público com o social e, portanto, com o político, com a sua etimologia na polis, cidade, coletividade. E o interesse coletivo opõe-se ao interesse individualizado, na educação e no seu serviço de supervisor.

A fim de se conhecer, analisar e controlar o que se passa dentro da escola e direcionar as inovações necessárias ao bom desempenho de suas funções, sem que se corra o risco de se tomar posições e medidas unilaterais e exclusivas a alguns setores, em desconsideração ou até em detrimento de outros setores e do conjunto, é preciso examinar a escola por meio de uma concepção sistêmica. Nesse sistema encontra-se a supervisão escolar, que no atual cenário da educação apresenta-se com suas riquezas e conflitos.

Segundo Motta $^{3}$ (1998,p.31), por sua própria função, a escola constitui-se em uma organização sistêmica aberta, isto é, em um conjunto de elementos (pessoas, com diferentes papéis, estrutura de relacionamento, ambiente físico, etc.), que interagem e se influenciam mutuamente, conjunto esse relacionado, na forma de troca de influências, ao meio em que se insere, e a supervisão nesse meio vem para acrescentar o processo educativo uma relação mais conjunta entre o profissional da supervisão e o corpo docente que de certa forma afeta diretamente o processo ensino /aprendizagem dos discentes. Dessa forma, qualquer mudança em qualquer dos elementos da escola (supervisor, docente e discente) produz mudança nos outros elementos.

De acordo com Nóvoa ${ }^{4}(2001$, p.34):

Com referência ao relacionamento de mútua influência com o meio em que está inserida, o que a torna um sistema aberto, e não fechado em si mesmo, sabe-se que a escola tem uma função de promover a melhoria da sua comunidade, pela educação de seus filhos, e que, ao fazê-lo, recebe influência dessa comunidade, adaptando seus objetos, programas, métodos e técnicas às suas necessidades. Também aí as mudanças são recíprocas. Portanto, quando se pensar em algum setor da escola, deve-se pensar em suas relações com os demais setores, bem como com a comunidade.

Nesse sentido percebe-se que o trabalho do Supervisor nesse contexto escolar atual influencia diretamente no dia-a-dia de educadores e alunos. Saber mediar às práticas do professor não é tarefa fácil, exige do supervisor uma avaliação sistematizada e constante da atuação do docente dentre outras questões.

\footnotetext{
${ }^{3}$ MOTTA, Paulo Roberto. Gestão contemporânea: a ciência e a arte de ser dirigente. Rio de Janeiro, Record, 1998.

4 NÓVOA, Antônio. Os Inspetores e a sua formação. 2. ed. Lisboa: Publicação Dom Quixote, Instituição de Inovação Educacional, 2001.p.34
} 
Saviani ${ }^{5}$ (1998, p. 14) afirma:

Se se entende a supervisão como a ação de velar sobre alguma coisa ou sobre alguém a fim de assegurar a regularidade de seu funcionamento ou de seu comportamento, vê-se que mesmo nas comunidades primitivas, onde a educação se dava de forma difusa e indiferenciada, estava presente a função supervisora.

Ao Supervisor Escolar compete fazer a leitura dos percursos de vida institucionais, provocar a discussão e a negociação de idéias, promover a reflexão e a aprendizagem em equipe, organizar o pensamento e a ação do coletivo das pessoas como indivíduos. Um supervisor deve estar disposto a aprender o tempo todo, a pesquisar, a investir na própria formação utilizando a criatividade, a inteligência, a sensibilidade e a capacidade de interagir com outras pessoas que estejam ao seu redor. Deve considerar que a sua responsabilidade vai além da sala de aula, colaborando na articulação entre escola e comunidade.

As novas concepções e atualizações que se referem à educação, mais precisamente nas teorias de desenvolvimento e aprendizagem, além do impacto dos meios de comunicação e informação, vêm colocando em questão e redefinindo o papel do educador e do supervisor na atualidade. Percebemos através de observações nas escolas, pesquisas bibliográficas e entrevistas que a ação do profissional da educação junto aos professores e alunos, ainda está muito aquém do determinado pelas teorias. O comprometimento do Supervisor e dos educadores com as transformações que ocorrem é fundamental e isso se dá através do diálogo entre os mesmos a fim de alcançar a construção da relação de mediação. Nesse sentido é possível que o Supervisor seja fonte de inspiração dos seus professores, conduzindo-os a uma reflexão crítica da realidade e do mundo.

Dessa forma a ação pedagógica do Supervisor Escolar na atualidade pode ser considerada um processo que tem por objetivo prestar ajuda técnica no planejamento, desenvolvimento e avaliação das atividades educacionais em nível do sistema ou unidade escolar, tendo em vista o resultado das ações pedagógicas, o melhor desempenho e o aprimoramento permanente do pessoal envolvido na situação ensino-aprendizagem. É também um processo que deve adaptar-se às várias circunstâncias do trabalho escolar Este processo pode assumir diferentes modalidades de atuação, no enfoque preventivo, construtivo e criativo.

\footnotetext{
${ }^{5}$ SAVIANI, Demerval. Escola e democracia. 27. ed. Campinas, SP: Editora Autores Associados, 1998, p. 14.
} 
O método preventivo: consiste em procurar constatar possíveis falhas no funcionamento pedagógico da escola, a fim de preveni-Ia antes que venha produzir resultados negativos. Visando antecipar-se, quando necessário, com medidas corretivas que venham a evitar possíveis falhas no processo educacional. Exemplo: Uma sala com alunos que estão em diversos níveis de aprendizado. Propor ao professor fazer um trabalho de recuperação paralela, trabalhando individualmente a dificuldade de cada um com o auxílio da equipe pedagógica.

O método construtivo: tem por fim auxiliar o professor a superar suas dificuldades, de maneira positiva, cooperativa, não-punitiva e nem avaliadora. Representa um trabalho cooperativo e participativo objetivando o crescimento profissional e pessoal do docente. Exemplo: Auxiliar o professor com a elaboração de planejamento/projetos, que venha a contribuir na sua prática pedagógica, estabelecendo um diálogo e uma orientação contínua. O fazer pedagógico faz-se necessário para o êxito do aprendizado tanto do educando, como do·educador em sua docência.

O método criativo: estimula e orienta o professor a buscar novas metodologias, a pesquisar e desenvolver atividades criativas na sua prática docente. Exemplo: É um trabalho de estímulo em que o supervisar orienta o educando a estar em constante capacitação e busca de novos jeitos de caminhar. A nova proposta requer um docente em constante pesquisa, pois o educador necessita criar aulas criativas e proporcionar a construção de uma consciência cidadã em seus educandos.

Em qualquer destes enfoques, torna-se necessário estabelecer um processo de comunicação sistêmica, orientado pelas etapas didáticas da atuação em Supervisão: Planejamento (pensar, definir objetivos, determinar procedimentos, programar); Organização: (estabelecer padrões, promover relacionamentos, distribuir funções, coordenar, delegar responsabilidades, comunicar); Orientação: (tomar decisões, selecionar pessoal, sugerir, incentivar, demonstrar, inovar); Controle (observar, regularizar, verificar) e Avaliação (sondar, julgar, avaliar).

Face ao contexto apresentado, faz-se necessário examinar o potencial do processo de supervisão para ser utilizado na escola pelo supervisor escolar.

De acordo com Nóvoa (2001, p.96): 
A Supervisão escolar é uma área de trabalho em educação cujas principais funções são relacionadas a uma forma de apoio ou assistência ao professor, ou a outro elemento significativo que participe do processo educativo promovido pela escola.

Esse apoio ou assistência, prestados nas mais variadas circunstâncias, baseia-se fundamentalmente num processo de inter-relacionamento pessoal e de comunicação.

Os aspectos de assistência, inter-relacionamento pessoal e comunicação constituemse em um processo de consultoria. Portanto, já que esses aspectos estiveram sempre presentes na atuação desses profissionais, principalmente do supervisor escolar, a consultoria não é exatamente uma nova forma de atuação (SILVA, 1997, p. 96).

A supervisão envolve uma concepção sobre o processo de assistência, que o direciona, dá-lhe sentido, concede-lhe maior objetividade e estabelece sua sistematização, com vistas a resultados mais significativos. O que pode caracterizá-la como inovação vem a ser a sua particularidade de sistematização, objetividade, direcionamento e sentido do processo de assistência.

Citando Nóvoa (2001, p.45):

Os princípios por trás do processo de supervisão seguem os preceitos de Confúcio, segundo os quais deve-se antes ensinar a pescar, que dar um peixe a quem lhe pede alimento. E todo o seu processo é direcionado por essa linha de ação: envidar todos os esforços para assistir a escola, o professor, os pais, não a resolverem um problema imediato, mas sim a desenvolverem, por meio da resolução desse problema, novas habilidades, percepções, entendimentos. Seu enfoque é o do desenvolvimento da escola como organização, pelo desenvolvimento dos seus recursos humanos, a fim de que, gradativamente, se torne mais eficiente na realização do processo educativo.

Com a expansão da finalidade da educação, de mera transmissão de conhecimentos para o de promoção do desenvolvimento integral do educando, em acordo com novos ideais e exigências sociais, a tarefa educativa do supervisor tornou-se mais complexa. O caráter dinâmico e multidimensional que toda ela deve ter impõe aos supervisores novas atitudes, habilidades e conhecimentos da atualidade.

Esta opinião pode ser vista nas palavras de Nóvoa (2001, p.12) relata que:

A supervisão passa de escolar, como é freqüentemente designada, a pedagógica e caracteriza-se por um trabalho de assistência ao professor, em forma de planejamento, acompanhamento, coordenação, controle, avaliação e atualização do desenvolvimento de processo ensino-aprendizagem. A sua função continua a ser política, mas é uma função sociopolítica crítica (...). 
Nesta perspectiva, na atualidade pode-se inferir que a supervisão está atrelada à gestão da escola como um todo. Uma vez que ele busca junto com o professor minimizar as eventuais dificuldades do contexto escolar em relação ao ensino-aprendizagem.

\section{CONSIDERAÇÕES FINAIS}

Ao término desse estudo, percebe-se que o papel do supervisor educacional tem como objetivo de trabalho articular crítica e construtivamente o processo educacional, motivando a discussão coletiva da comunidade escolar acerca da inovação da prática educativa cujo fim é garantir a qualidade do ensino, o ingresso, a permanência e o sucesso da instituição de ensino.

Constatou-se que o supervisor deverá ser o mediador da relação de trabalho dos diferentes segmentos educacionais. O trabalho do supervisor deverá ser baseado em uma prática reflexiva e uma postura de parceria, assim o papel do supervisor, já que também é um educador e deve estar comprometido com a construção da aprendizagem significativa.

O Supervisor deve estar sempre pautado numa postura ética, numa prática reflexiva para que junto com os demais envolvidos na educação, tenham como meta final a aprendizagem e a assimilação, por parte dos alunos, de conteúdos relacionados com o mundo atual, e todo este trabalho será mais eficaz se o supervisor for então este articulador do processo de ensino - aprendizagem tendo uma atuação direta com os docentes.

\section{REFERÊNCIAS BIBLIOGRÁFICAS}

FERREIRA, Naura S. C. Supervisão Educacional para uma escola de qualidade: formação a ação. 4 ed., São Paulo: Cortez,2003.

MOTTA, Paulo Roberto. Gestão contemporânea: a ciência e a arte de ser dirigente. Rio de Janeiro, Record, 1998.

NÓVOA, Antônio. Os Inspetores e a sua formação. 2. ed. Lisboa: Publicação Dom Quixote, 
Instituição de Inovação Educacional, 2001.

SAVIANI, Demerval. Escola e democracia. 27. ed. Campinas, SP: Editora Autores Associados, 1998. 